\title{
El consumo como escenario para la "forja de si" en las categorías cuerpo y salud: una mirada desde la psicología humanista existencial ${ }^{*}$
}

\author{
Norela Ortiz Pahón \\ Universidad Pontificia Bolivariana, Medellín, Colombia \\ noreortiz@gmail.com
}

\section{RESUMEN}

Este artículo plantea una reflexión teórica sobre los valores existenciales en el consumo como fenómeno social. Se definió como marco teórico la psicología humanista existencial y se delimitó el análisis al cuerpo y la salud, categorías de interés para la psicología, el mercadeo y la publicidad. Se acudió a la investigación cualitativa con una revisión bibliográfica de tipo hermenéutico. Estas categorías remitieron a las nociones de "cuidado de sí" y de "forja de sí", las cuales son necesarias para que el hombre se oriente, si es su elección, a una "buena vida". Se encontró como línea temática vinculante el límite como inherente a la libertad y a la responsabilidad. El estudio finalmente permitió comprender que la "forja de sí" y el "cuidado de sí" están enmarcados dentro de ese ejercicio del límite, la libertad y la responsabilidad. Si bien en las categorías cuerpo y salud el hombre de hoy tiene prácticas para "cuidar de sí", estas están atravesadas por las dinámicas de mercado que lo orientan hacia lograr un cuerpo y una salud idealizados, medicalizados y funcionales para el trabajo y la productividad, así como para experiencias de goce hedónico que lo esclavizan y no necesariamente lo conducen a una "forja de sí".

Palabras clave: límite; libertad; responsabilidad; cuidado de sí; publicidad; mercadeo.

* Cómo citar: Ortiz Pabón, N. (2019). El consumo como escenario para la "forja de sí" en las categorías cuerpo y salud: una mirada desde la psicología humanista existencia. Ciencias Sociales y Educación, 8(15), 41-64. DOI: https://doi.org/10.22395/csye.v8n15a3

Recibido: 6 de noviembre de 2018.

Aprobado: 7 de marzo de 2019. 


\section{Consumption as an Scenery for the 'Forging of the Self' in the Body and Health Categories: a Perspective from the Humanistic Existential Psychology}

\section{ABSTRACT}

This article raises a theoretical reflection upon the existential values in consumption as a social phenomenon. The existential-humanistic psychology was defined as a theoretical framework and the analysis was delimited towards the body and health, interesting categories for psychology, market, and advertisement. Qualitative research was used with a bibliographic review of hermeneutic kind. These categories allowed the use of notions such as "care of the self" and "forging of the self", which are necessary for the orientation of men if he or she chooses to, towards a good life". It was found as a binding theme line the limit as inherent to freedom and responsibility.
The study finally allowed to comprehend that the "forging of the self" and "the care of the self" are framed under this exercise of limit, freedom, and responsibility. Even if within categories such as body and health men and women can dispose of practices for the "care of the self", these are crossed by market dynamics orientating for a idealized, medicalized "body" and "health" and functional towards work and productivity, as well as hedonic pleasure experiences that enslaves him or her and not necessarily points towards a "forge of the self".

Keywords: limit; freedom; responsibility; care of the self; advertisement; marketing.

\section{O consumo como cenário para a "forja de si mesmo" nas categorias corpo e saúde: um olhar a partir da psicologia humanista existencial}

\section{RESUMO}

Este artigo reflete, de forma teórica, sobre os valores existenciais no consumo como fenômeno social. Foi definida, como referencial teórico, a psicologia humanista existencial e foi delimitada a análise do corpo e da saúde, categorias de interesse para a psicologia, para o marketing e para a publicidade. Recorreu-se à pesquisa qualitativa com uma revisão bibliográfica de tipo hermenêutico. Essas categorias remeteram às noções de "cuidado de si" e de "forja de si mesmo", as quais são necessárias para que o homem se oriente, se for sua escolha, a uma "boa vida". Verificou-se, como linha temática vinculante, o limite como inerente à liberdade e à responsabilidade. Este estudo permitiu compreender que a "forja de si mesmo" e o "cuidado de si" estão delimitados dentro desse exercício do limite, da liberdade e da responsabilidade. Embora, nas categorias corpo e saúde, o homem de hoje tenha práticas para "cuidar de si", estas estão permeadas pelas dinâmicas de mercado que o orientam a ter um corpo e uma saúde idealizados, medicalizados e funcionais para trabalhar e produzir, bem como experimentar o gozo hedônico que o escraviza e não necessariamente o leva a uma "forja de si mesmo".

Palavras-chave: limite; liberdade; responsabilidade; cuidado de si; publicidade; marketing. 


\section{Introducción}

Las marcas son la forma en que las empresas de bienes y servicios interactúan directamente con sus públicos. A través de la creación conjunta de imaginarios simbólicos que atraviesan las creencias y los valores de las personas, pueden llegar a proponer a sus comunidades de interés unos modelos de comportamiento que orientan las formas de vida que eligen, lo que conlleva un gran reto y una gran responsabilidad a empresas y consumidores de hoy.

Las personas asimilan las marcas gracias a su capacidad de representación, la cual le es propia por estar dotadas de lenguaje. Es así como las vuelven parte de su vida cotidiana y establecen con ellas unas relaciones que van más allá de la mera satisfacción de una necesidad funcional.

Esta capacidad le permite distinguirse a sí mismo del mundo exterior, le posibilita vivir en un tiempo pasado o futuro, le permite hacer planes para el porvenir, utilizar símbolos y usar abstracciones, verse a sí mismo como lo ven los demás y tener empatía con ellos, comenzar a amar a sus semejantes, tener sensibilidad ética, ver la verdad, crear la belleza, dedicarse a un ideal, y, quizá, morir por él. Realizar estas posibilidades es ser persona. (Martínez, 1982. p. 75)

Tal como lo plantea Vargas (2014), las personas consumen representaciones más que productos o servicios en sí y desde esas representaciones les otorgan un sentido a las marcas que eligen:

Existe un conjunto de elementos de carácter simbólico asociados a los productos del mercado, lo cual hace que muchos productos no importen tanto por su potencial para cubrir las necesidades básicas sino porque nos permiten identificarnos o diferenciarnos de los demás consumidores. (p. 19)

En los entornos competitivos que se tienen hoy, las personas constantemente están evaluando y decidiendo en función del impacto que las marcas les generan con sus estrategias de persuasión, sin que este impacto sea de carácter consciente para ellos.

La publicidad tiene un lugar relevante en este proceso, pues su objetivo es la comunicación intencionada de las propuestas que las marcas hacen a las personas. El proceso a través del cual las marcas logran ese contacto se requiere para el inicio de una posible relación y el establecimiento de esta. Este trabajo es cada vez más complejo para las marcas, pues cada día el desarrollo del mercado y de las sociedades permite la aparición de nuevas posibilidades de relación, con lo que la atención de las personas en los públicos de interés se dispersa gracias a la cantidad de información y la decisión se complejiza de manera significativa (Schiffman y Kanuk, 2010). 
Esta situación lleva a pensar en el tema de la elección de las marcas por parte de sus consumidores, el cual constituye el marco general del objetivo de este artículo y dirige la atención a la gestión de la marca. Esta gestión tiene como función administrar todos los procesos, tanto la creación de una marca, como su posicionamiento en el mercado y el mantenimiento o mejoramiento de éste, en lo cual se incluye la actividad publicitaria. Molina y Morán (2008) definen la gestión de marca como:

Un sistema peculiar para comprender y manejar la totalidad de las relaciones, de los diálogos entre las empresas y sus mercados; abarca desde la percepción de las necesidades hasta su satisfacción lógica y emocional a fondo y por largo plazo para que la empresa y sus compradores obtengan los máximos beneficios. La gestión de marca procura el éxito de aquellas empresas que contribuyen al éxito de sus mercados. (p. 71)

De lo anterior se desprende que la gestión de marca es la encargada de definir también los diferentes públicos de interés. Para ello, acude a las actividades de investigación y análisis del consumidor, tema que pertenece a la disciplina del Comportamiento del Consumidor. En este contexto la psicología ha realizado grandes aportes, en particular a partir de la perspectiva cognitivo conductual, que se centra en el análisis de procesos sensoriales, perceptivos y cognitivos en general. De esta manera, la psicología ha contribuido al desarrollo de la estrategia de mercadeo a través de la generación de aprendizajes que crean altos niveles de involucramiento en sus consumidores (Solomon, 2013).

Participar en el mercado hoy exige que las marcas hagan un gran esfuerzo para poder permanecer, por lo cual se corre el riesgo de traspasar fronteras y de atentar contra los principios existenciales de vivir una "buena vida". Recordando la referencia al Capitalismo Estético que hizo el profesor Lipovetsky (2017) como invitado especial en la Escuela de Verano de la Universidad Pontificia Bolivariana, el riesgo se concreta en que "el consumo no puede ser la pasión humana, porque el consumo es una pasión fría y vacía". Aunque promete felicidad, no necesariamente garantiza la realización de la vida, entendida esta como proyecto existencial.

Se puede decir que las empresas podrían aportar desde su comunicación de marca, sus productos o servicios, acciones dirigidas a la búsqueda de mejores condiciones de vida para sí mismas y para las personas a las cuales se dirigen. Esas mejores condiciones de vida tienen que ver con la noción de "vida buena" (Savater, 2004) que es asunto de interés relevante para la psicología y también para la ética.

También es importante decir que las marcas y los consumidores están implicados en esta tarea. Se exige a cada uno participar en esta dinámica de 
manera responsable, en ese ejercicio de la libertad que propone la vida desde una mirada existencial y que constituye uno de los temas de la reflexión teórica que este artículo contiene. Hay que precisar que no solo las marcas tienen derechos y obligaciones, sino que los consumidores también los tienen, tal como lo contemplan los principios que rigen el derecho del consumidor y que se consagran en la Ley 1480 de 2011 del Congreso de la República de Colombia.

Ahora bien, al tener presente que las personas hoy están movilizadas por las propuestas que las marcas y el consumo les proponen, surge la pregunta investigativa por la capacidad que tienen las marcas para intervenir las decisiones que se dan en la experiencia de la vida de los consumidores y hasta qué punto las condiciones existenciales de elegir y decidir en libertad están condicionadas por ello. Se ha acudido a la investigación cualitativa a través de la revisión bibliográfica de textos propios del tema y bajo un acercamiento de tipo hermenéutico, sobre el cual López (2001) plantea que "se comprende que la hermenéutica implica, como enfoque de investigación, una labor a través de la cual el investigador busca comprender e interpretar un fenómeno o realidad en un contexto concreto" (p. 82).

Se ha delimitado el análisis a las categorías cuerpo y salud, las cuales constituyen categorías de interés psicológico, porque son experiencia de la condición de límite. También son términos del consumo, el mercadeo y la publicidad, en tanto han constituido un escenario a través del cual las marcas han ejercido gran influencia en la modificación de conducta social y, por ende, en el comportamiento de los consumidores.

Pensar en las categorías de cuerpo y salud, en el marco de los valores existenciales, remitió a las nociones de "cuidado de sí" y de "forja de sí" (Foucault, 2012, p. 113 citado por Estrada Mesa, 2016 p. 143), las cuales son necesarias para que el hombre se oriente, si es su elección, a una "Buena Vida" (Savater, 2004; Canga Sosa, 2017; Papalini, 2017).

Ahora bien, en relación con sus representaciones en la antigüedad, surge la pregunta por si las prácticas asociadas al cuerpo y la salud hoy, entendidas estas últimas como materializadoras de experiencias de consumo, contribuyen de alguna manera a esa "forja de sí". Esta es la pregunta central de este trabajo.

El recorrido por los diferentes temas permitió encontrar una línea temática vinculante: el límite como inherente a la libertad y a la responsabilidad. Fue así como el estudio finalmente permitió comprender que tanto la "forja de sí", esa experiencia de formación para la vida a través de la autorregulación y el fortalecimiento de la voluntad, como el "cuidado de sí" entendido este como consciencia y hábitos para la preservación de la vida, están enmarcados dentro de ese ejercicio del límite, la libertad y la responsabilidad. Si bien en las 
categorías cuerpo y salud el hombre de hoy realiza prácticas para cuidar de sí, estas categorías están atravesadas por las dinámicas de mercado que lo orientan hacia lograr un cuerpo y una salud idealizados, medicalizados y funcionales para el trabajo y la productividad, así como para experiencias de goce hedónico que lo esclavizan, y no necesariamente lo conducen a una "forja de sí".

Es importante esclarecer que la relación consumo-libertad surge como emergente en la presente investigación y abre un nuevo campo de profundización en la inquietud investigativa que dio origen al presente artículo. Además, si bien el límite constituye uno de los valores existenciales, termina imponiéndose como el resultado central de la investigación: el problema de la capacidad de una marca para intervenir en las decisiones de los consumidores es un asunto que atañe al valor existencial de la libertad en tanto invita a una consciencia de límite.

\section{La psicología humanista existencial y el límite}

La psicología humanista existencial tiene una mirada holística y comprende al hombre como un ser integrado y diferenciado que tiene una tendencia hacia la autorrealización: "el hombre muestra capacidad, y también deseo, de desarrollar sus potencialidades. Parecería que esto se debiera a una motivación suprema: una necesidad o motivo fundamental que orienta, da energía e integra el organismo humano" (Martínez, 1982. p. 73). Esto quiere decir que el hombre se orienta al desarrollo de sus capacidades y a la trascendencia de sus limitaciones para ser capaz de alcanzar experiencias de realización que incluyen también la dimensión espiritual. Quitmann (2006), se refiere de la siguiente manera a los elementos que delimitan el interés de la psicología humanista:

La psicología humanística puede definirse como la tercera rama fundamental del campo general de la psicología (las dos ya existentes son la psicoanalítica y la conductista) y como tal trata en primer término de las capacidades y potenciales humanos que no tienen lugar sistemático ni en la teoría positivista ni en la conductista, o en la teoría clásica del psicoanálisis; p. ej., creatividad, amor, sí mismo, crecimiento, organismo, necesidad básica de gratificación, autoactualización, valores superiores, ser, devenir, espontaneidad, juego, humor, afecto, naturalidad, calor, trascendencia del ego, objetividad, autonomía, responsabilidad, salud psicológica y conceptos relacionados con ellos. (p. 29)

Esta corriente psicológica se basa para su definición en los postulados de la filosofía existencial que plantean que el hombre es finito, lo cual deriva en la realidad de que un día morirá y todo acabará. La evidencia de que la vida "un día acaba" lo lleva a situaciones de miedo, lo confronta con la soledad y se constituye en fuente de angustia para él: "[...] desamparado, solo ante la nada, arrojado a una realidad incomprensible y absurda, marcado por el miedo" (Quitmann, 2006. p. 45). 
En esa situación de angustia el hombre tiene la posibilidad de elegir cómo enfrentarla, es decir, puede elegir sumirse en el miedo y la soledad cerrándose así a la vida o puede elegir actuar sobre su propia vida: "no es posible no elegir, ya que incluso la no elección es una posibilidad específica, es decir, una elección" (Martínez, 2009. p. 55).

Al elegir y actuar, el hombre, quien cuenta con capacidades de reflexión e interacción social, puede optar por otorgar sentido a su vida a partir de sus valores los cuales son una guía para su vida, le permiten una autorregulación y lo dirigen en sus decisiones y actos: "La perspectiva existencial se caracteriza por un intento de contemplar la realidad humana desde la cotidiana búsqueda de sentido, por lo que es posible decir que es tan antigua como la humanidad" (Martínez, 2009. p. 37). Hay que tener en cuenta que, desde esta perspectiva, sean cuales sean sus decisiones, el hombre debe encargarse responsablemente de estas y de las implicaciones que tengan para sí mismo, para los otros y para lo otro. Decidir y responsabilizarse depende del nivel de madurez del individuo según su proceso de desarrollo.

En el decidir y responsabilizarse subyace una condición más definitiva desde esta perspectiva: el hombre es un ser libre, "la libertad y las renuncias que implica son hechos fundamentales de la existencia" (Martínez, 2009. p. 55). Este hecho plantea un gran reto acerca de cómo quiere orientar su vida porque sabe que siempre enfrentará limitaciones que le vienen del ambiente en que vive, en particular el de la naturaleza, de su propia condición de ser humano con una biología y una historia personal, así como de la sociedad que lo ha acogido.

Es importante recalcar que el carácter de finito conduce al hombre a una conciencia de límite, es decir, a saberse un "ser-para-la-muerte", con una condición de "arrojado" sobre la cual Martínez (2008), citando a Heidegger, dice: "Lo que hace que todo importe es el hecho de que todo es finito y que, para mí, todo terminará con mi muerte" (p. 160) y en relación con esta condición de límite, este mismo autor habla de la libertad: "la libertad consiste no en no tener límites sino en la obligación que esos límites nos imponen: el tener que elegir" (p. 162). Sobre este mismo aspecto de la libertad y el límite, Cortina (2002) dice que "Libertad no significa ausencia de leyes, sino orientarse por las propias leyes, por leyes humanizadoras" (p. 30). Lo anterior plantea que la libertad lleva al límite y que, a su vez, el límite existe porque hay libertad como posibilidad.

Esta conciencia de límite es la que le permite al individuo dar un sentido a su vida al reconocer que a lo largo de esta se irá forjando según el sentido que ha elegido y al considerar que lo que elige no es tanto las cosas que le suceden, de las cuales muchas veces no tiene control, sino la manera en que responde a estas (Savater, 2004, p. 28). 
En este orden de ideas, los postulados de elegir y decidir en condiciones de una libertad con límites según la psicología humanista existencial, que también se extiende a la dimensión del hombre consumidor, constituyen el escenario de análisis de la presente investigación que pretende dar una mirada al lugar del consumidor inmerso en el fenómeno del poder que tienen las marcas para influir en la toma de decisiones y en el comportamiento.

Para delimitar el análisis se eligieron las categorías cuerpo y salud. Se hizo una aproximación a éstas desde la perspectiva de la psicología humanista existencial que permite establecer que ambas actúan como expresión de la condición de límite a la que el hombre está sujeto y que son concreción de la experiencia de significación de la vida, así como desde la perspectiva del mercadeo y la publicidad en la que cuerpo y salud son categorías de consumo relevantes para el hombre de este tiempo.

Para la mirada de la psicología humanista existencial, el cuerpo es una configuración biológica que determina al hombre y le informa que no todo lo puede alcanzar por sus características físicas, pues se agota y se debilita por el paso de los años y por el cuidado que se haga de él, con lo que se limita o potencia su posibilidad de experiencia de la vida. Pero, más allá de una organización física, esta perspectiva plantea que el cuerpo es el medio a través del cual se vive la experiencia, pues es la conexión con el mundo perceptual y con éste se conduce a la búsqueda de la autorrealización. Respecto del cuerpo desde esta perspectiva, Ortiz-Pabón y Sanabria-Correa (2015) apoyándose en Martínez (2009) plantean que:

En la psicología humanista existencial, para hablar de cuerpo se parte del "cuerpo vivido" desde el cual se comprende que, el cuerpo es más allá de lo físico, es una totalidad que se concreta en experiencia y no solo significación de órganos con sus funciones y disfunciones; es el lugar de la percepción y con él y desde él, el ser humano se lanza a la experiencia de la vida, se articula en ella y conforma su ser-en-el-mundo. [...]. El cuerpo actualiza en el ser humano la conciencia de angustia, una dimensión de la conciencia de límite, pues el cuerpo le impone al hombre unas condiciones físicas que éste debe reconocer para poder significar y establecer contacto con el mundo. (p. 7)

De manera similar, la Salud va más allá de una funcionalidad de órganos y sentidos. De ella depende en gran medida la posibilidad de actuar libremente en la búsqueda de la autorrealización, pues limitará o potenciará dicho impulso según sea la vivencia que el individuo tenga de ella. En esta lógica de pensamiento, la salud no es ausencia de enfermedad. Más bien, plantea que hay salud cuando el hombre puede desarrollar de manera plena sus capacidades para transformar sus limitaciones y entender la enfermedad como una oportunidad de resignificación de la existencia. Según Latner (1994), citado en Ortiz-Pabón 
y Sanabria-Correa (2015), "cuando tenemos salud estamos a tono con todas nuestras capacidades y con el proceso que nos hace ser lo que somos. Nos identificamos con todas estas funciones vitales" (p. 51).

Ahora bien, Ortiz-Pabón y Sanabria-Correa (2015) dejan ver que cuerpo y salud se integran en tanto ambas son concreción de la experiencia de la vida, permiten una resignificación de esta y conducen al hombre a la autorrealización. Estas autoras proponen entonces una categoría que permite definir la relación entre ambas nociones como una "unidad experiencial significada" y describen esta relación de la siguiente manera:

Desde la perspectiva de la psicología humanista existencial, la relación entre las categorías cuerpo y salud es, ante todo, una relación de holismo, una relación de unidad y totalidad, y tal unidad se da en la experiencia, entonces podemos hablar de una unidad experiencial. [...]. Por consiguiente, al comprender que la relación cuerpo-salud es unidad experiencial, será posible vislumbrar y comprender que esta experiencia debe significarse en la vivencia, por tanto, puede hablarse de que la Unidad Cuerpo-Salud es experiencia significada. [...]. Así entonces, se puede plantear que la unidad experiencial cuerpo-salud es una experiencia que se significa y esa significación otorgada a dicha relación es precisamente la forma de ser-en-el-mundo. (p. 16)

A partir de esta última concepción se plantea que cuerpo y salud, ante todo, son experiencia y una dimensión particular de esta es la de límite, propia de la característica de finitud del hombre que se concreta en unas condiciones físicas que él debe comprender y significar para poder establecer un lugar en el mundo (Ortiz-Pabón y Sanabria-Correa, 2015). Sobre este tema de la experiencia, De Castro y García (2001) citan a Romero (2003), en relación con el hecho de que para estudiar la experiencia no basta con llegar a los comportamientos, sino que lo relevante es conocer las formas cómo el individuo configura su propio mundo, es decir, cómo significa lo que vive:

Las vivencias se articulan y organizan constituyendo los rasgos peculiares de la persona, es decir, las formas características que tiene un individuo de establecer la trama del mundo personal. [...]. La experiencia se objetiva en comportamientos, mas solo lo hace de manera parcial; lo más íntimo de la persona es apenas vivido por ella: esto es lo más propio de la subjetividad. (p. 30)

Entender al cuerpo y la salud desde la perspectiva de la psicología humanista existencial permite pensar que el hombre configura los marcos de su realidad a partir de las significación que hace de los límites que le establecen el cuerpo y la salud. Además, deja pensar en la posibilidad que tiene el hombre de actuar en aras de preservarse en la vida (cuidado de sí), para lo cual ha de atenderse en esas dimensiones y lo que le exige, así como desarrollar una cierta capacidad de autogestión (forja de sí). Estos elementos intervienen en el dirigirse a la autorrealización y se desarrollarán en el siguiente apartado para permitirnos preguntarnos 
por la influencia de las marcas en las elecciones y el comportamiento de los consumidores, esto es, si el consumo puede ser un escenario para la forja de sí y, en particular, cómo puede darse ello en las categorías de consumo: cuerpo y salud.

\section{El "cuidado de si" y la "forja de si": Límite, libertad y responsabilidad que se viven en el cuerpo y la salud}

La noción de "buena vida" está en directa relación con la autorrealización y es lo que, desde la perspectiva de la psicología humanista existencial, se espera que el hombre alcance a través de sus experiencias de vida. Para ello deberá cuidar de sí y forjarse un carácter, reconociendo la necesidad de límite frente a sus impulsos instintivos, así como en la interacción con el otro, en la significación de lo otro, y, en particular, para direccionar su desarrollo en el marco del sentido de vida que ha elegido (Canga Sosa, 2017; Papalini, 2017).

Savater (2004) habla de la buena vida y permite comprender que si la libertad es una característica del hombre, la responsabilidad es una exigencia para él si quiere tener una buena vida. Según este autor, el hombre ético hace un uso responsable de su libertad al elegir opciones "buenas", es decir, las que le son convenientes porque le permiten preservarse y preservar al mundo sin daño: sin dañarse, sin dañar al otro ni a lo otro. Sobre esto dice:

Yo creo que la primera e indispensable condición ética es la de estar decidido a no vivir de cualquier modo: estar convencido de que no todo da igual, aunque antes o después vayamos a morirnos. [...]. Comprender por qué ciertos comportamientos nos convienen y otros no, comprender de qué es la vida y qué es lo que puede hacerla 'buena' para nosotros los humanos. (p. 88)

Lo anterior plantea que el hombre ha de desarrollar una capacidad de discernimiento que le exigirá establecer ese límite para sí mismo, para el otro y para lo otro a partir de los condicionantes fundamentales que se imponen en relación con el cuerpo y la salud. Surge así la idea de Savater (2004) de hacerse una buena vida que, más que un simple hacer a capricho, es forjarse, templar el carácter para poder elegir lo que conviene y lo que no: "Es importante ser capaz de establecer prioridades y de imponer una cierta jerarquía entre lo que de pronto me apetece y lo que, en el fondo, a la larga, quiero" (p. 68).

En este orden de ideas, se introduce la noción de "cuidado de sí" que puede enmarcarse dentro del valor existencial de la responsabilidad y que llama a que el hombre se encargue de hacer su propia existencia eligiendo y teniendo en cuenta que el marco del "cuidado de sí" apunta a la preservación de la vida y la disminución, en tanto pueda preverse y sea posible, de los riesgos de que se pueda perder o dañar. 
El "cuidado de sí" implica al cuerpo y la salud porque son escenarios para materializar las prácticas en torno a la preservación de la vida, así mismo son experiencia de significación de la vida en la que el "cuidado de sí" es un valor para otorgar sentido y orientarse a la buena vida y a la autorrealización del hombre.

Por otro lado, Estrada-Mesa (2016) cita a Foucault (2012) para precisar más esta relación entre el "cuidado de sí" con las categorías cuerpo y salud. En este sentido sugiere que en la antigüedad se entendía que tener salud era tener libertad, en tanto el hombre no estaba condicionado a atender las exigencias de un cuerpo enfermo que implicara abandonar o restar atención a otros asuntos, sino que lo que el hombre debía hacer era, en efecto, "cuidar de sí" para poder vivir bien. Esta era la razón de su estar en el mundo. Ese vivir bien era justo una vida que hace uso de la libertad, lo cual conllevaba a poner unos límites al cuerpo, para que éste pudiera garantizar tal vida en libertad. Al respecto en esta misma cita el autor plantea:

Además, dar salud al cuerpo hace que la vida transcurra de una forma libre [...] ya que un cuerpo con mala salud tiene como consecuencia el desvarío, el desaliento, el mal humor, la locura, hasta el punto de que los conocimientos adquiridos acaban por ser expulsados del alma. (p. 143)

"Cuidar de sí" es, ante todo, una elección que se vive en el cuerpo y la salud. Constituye una parte fundamental de la tarea existencial del hombre de irse haciendo cada vez más sí mismo, cada vez mejor ser humano, si esa es su elección, claro está. Ese irse haciendo no se refiere a una opción en aislamiento, sino que implica un reconocimiento del otro como un activo co-participante de la construcción en un contexto donde lo otro, entendido como lo que no pertenece a la especie humana, también tiene un lugar por la posibilidad de la significación que le otorga el lenguaje al ser humano.

Este ejercicio de cuidar de sí mismo implica un nivel de responsabilidad que pone al hombre en condición de limitación, en la realidad de que no puede acceder siempre a todo, en especial a la descarga de sus instintos y a las demandas impulsivas de sus deseos, bien sean meramente biológicos o aprendidos. Y es justo en esa experiencia de límite, de sentirse condicionado por un riesgo de daño a sí mismo, hacia el otro o hacia lo otro, o por el simple hecho de reconocerse en una condición de no posibilidad, lo que le permitirá fortalecer su voluntad, autogobernarse, forjarse. Es por esto por lo que se propone pensar que el consumo tiene muchas posibilidades como escenario para el desarrollo de la forja de sí.

Respecto al autogobierno, Estrada-Mesa (2016) reflexiona acerca de la norma y su necesidad en la regulación del colectivo con fines adaptativos. Propone que, 
si bien la norma suele estar dirigida al control de masas, esta también ha de ser pauta para la regulación de sí mismo. Esto quiere decir que los individuos deben tener una capacidad de autogobierno, que compromete el valor existencial de la responsabilidad y toma forma en las capacidades de elegir y decidir, lo cual lleva al principio ético de autonomía (Franca-Tarragó, 2008). El autogobierno conduce a una noción de "forja de sí" que ha de revelarse concretamente en las diferentes dimensiones de la vida, entre ellas la del consumo.

Estrada-Mesa (2016), cita a Laval y Dardot (2013) para proponer que "la cuestión del gobierno, comprendido en este caso como una actividad y no como una institución, dará cabida a las dinámicas de la autoconducción" (p. 139). Por otro lado, Cortina (2002) también menciona la cuestión en los siguientes términos:

Las personas -se ha dicho también- son autónomas, autolegisladoras (Kant). Y esto significa que son capaces de darse leyes por las que están dispuestas a sacrificar incluso su impulso natural al egoísmo. Una vida en plenitud, desde esta perspectiva, es la de quien orienta su vida por las leyes de la humanidad, liberándose de cualquier sujeción extraña a ellas. (p. 30)

Nótese, entonces, que la "forja de sí" constituye también una experiencia que está en relación directa con el "cuidado de sí": cuidar de sí lleva a la "forja de sí" porque implica una experiencia de límite que se concreta en renunciar a asuntos que puedan resultar dañinos, pero a su vez para cuidar de sí, es necesaria la forja, esto es, la fuerza de voluntad que permite que el individuo pueda hacer tales renuncias. Ambas dimensiones se viven en la experiencia, en el mundo que el individuo va configurando. Están condicionadas por el cuerpo y la salud porque son, en buena medida, las encargadas de activar la conciencia de límite y porque las prácticas en torno a la forja, al igual que las del cuidarse, se materializan en ellos.

Hasta este momento de la presente reflexión se identifica un hilo conductor que no solo vincula las nociones de "buena vida", "cuidado de sí" y "forja de sí", sino que también conecta con las nociones "cuerpo" y "salud", así como con los lineamientos de la psicología humanista existencial. Este hilo es el límite. La condición de finitud condiciona la consciencia del hombre para asumir que su vida tiene un fin porque se acaba. Esta consciencia de límite está activa permanentemente en la vida del hombre a través de la experiencia cotidiana que se vive en el cuerpo y está condicionada también por las posibilidades de realización plena de sus potenciales, de la salud. El cuerpo y la salud entendidas como experiencia también permiten materializar el "cuidado de sí" y la "forja de sí" que son en sí mismas experiencias de límite porque le exigen al individuo consciencia, esfuerzo y renuncias. Son las vías a través de las cuales él se orienta a la búsqueda de una "buena vida" para dirigirse a la autorrealización. 
El límite es un componente de la libertad y de la responsabilidad. Este tema permite pasar al último apartado del presente artículo que una pregunta sobre si el consumo como tal puede ser escenario para la "forja de sí". En este se precisa mucho más el marco de reflexión sobre el tema de la capacidad de las marcas para intervenir en las elecciones y decisiones del consumidor a partir de las categorías de consumo cuerpo y salud.

\section{El consumo como escenario para la "forja de si" en las categorías "cuerpo" y "salud"}

Desde la experiencia de límite y la posibilidad de significar que se ha expuesto, puede decirse que el cuerpo y la salud también constituyen escenarios para el "cuidado de sí" y la "forja de sí", los cuales toman una forma concreta a través de las prácticas que el individuo realiza al intervenir sobre ellos con la intención de preservarse en la vida, si es su elección hacerlo. La pregunta consiste en si esta lógica abarca también las prácticas de consumo del hombre de hoy, las cuales son en sí mismas experiencias que implican el cuerpo y la salud directamente. Se puede retomar aquí el tema del poder que tienen las marcas sobre las elecciones de sus consumidores y, con ello, dar un paso adelante en esta reflexión para analizar las relaciones entre el consumo, el límite, la libertad, el cuerpo y la salud, implicadas en las nociones de "cuidado de sí" y "forja de sí". De esta manera, se intentará establecer si en el marco de las categorías cuerpo y salud, el consumo constituye un escenario para la "forja de sí" que también puede llamarse "forja del carácter" o "forja de la voluntad".

En este momento es necesario hacer un alto para ver que las relaciones entre las nociones "cuidado de sí" y "forja de sí" han variado a lo largo de la historia, esto es, si "el cuidado de sí" ha dejado de ser lo que en la antigüedad se consideraba una experiencia íntima de "forja de la voluntad" para convertirse en un tema más desde el cual el mercado ejerce un control social.

En la antigüedad "cuidar de sí" era un ejercicio de la libertad en tanto se optaba por el uso sereno y consciente de las pulsiones del cuerpo como un ejercicio de autorregulación y, por tanto, de límite. Estrada Mesa (2016) refiere que la medicina era le encargada de proponer las prácticas para lograrlo y de educar al sujeto sobre tales menesteres con el propósito filosófico de una formación en torno a la voluntad, entendida esta como la capacidad de autogestión en libertad y responsabilidad, con el fin de preparar a los individuos para afrontar las situaciones complejas de la vida, decidir frente a ellas y en esa medida "irse haciendo" hombre:

Por supuesto, esta serie de prescripciones encaminadas al gobierno de uno mismo no sólo tenía efectos sobre el plano somático. Se formaba una vida ejercitante para "templar" el alma. El rigor de una vida ascética que involucra exigencias 
físicas requiere de un semblante firme. (Foucault, 2012, p. 113 citado por Estrada Mesa, 2015, p. 143)

Para el hombre contemporáneo la noción "cuidado de sí" también está hoy muy conectada con la medicina y, por tanto, con el cuerpo y la salud (Lipovetsky, 2016). No solo se refiere a acudir a las terapéuticas médicas y psicológicas que pasan por las llamadas "terapias alternativas", sino a las prácticas espirituales diversas, a la alimentación, a la actividad física, el sueño, el sexo, el relacionamiento, el entretenimiento, entre muchas otras, pero bajo una lógica de mercado. Esto quiere decir que estas prácticas hoy se configuran en actos de consumo y operan, según lo plantea Estrada-Mesa (2016), bajo unas dinámicas en las cuales están alejadas de una intención de formación del sujeto en torno a la voluntad y el carácter para la vida. Parecen estar orientadas, más bien, a un propósito económico donde el interés ya no es tanto el desarrollo de un individuo para la libertad, sino para la generación de riqueza material.

Esta mirada del "cuidado de sí", atravesada por las influencias del mercado, lleva a pensar en las formas de ser del hombre de hoy que suelen estar dirigidas a la producción, lo cual implica un modo de vivir orientado a ser eficiente, no solo en el uso de los recursos sino en la experiencia de la vida misma. El cuerpo y la salud se ponen allí como medios para lograrlo y como medios de apropiación de esa forma de vida, creándolo y adaptándolo para tal fin y viviendo las propuestas de cómo hacerlo desde unas estructuras económicas, entre ellas las marcas comerciales, pues estas definen más unas especies de poder de unos sobre otros que del poder sobre sí mismo, en una intención más de regulación heterónoma que autónoma para el sujeto. En este sentido, se buscan unos tipos de bienestar que posibilitan su integración con los aparatos productivos y las demandas de los mercados. Al respecto, Fajardo (2009), habla de la siguiente manera:

El increíble torrente de imágenes proporcionada por los medios promueve de forma activa este estilo de "vida eficiente y saludable" alimentando una imagen de mercado donde se combina la estética y la salud. Fitness and health es el nuevo lema de mercado que parece generar una sensación de confianza en los consumidores, utilizado para vendernos yogurt, colchones, aceites, cereales, casas, ropa interior e inclusive políticos de ética dudosa. (p. 46)

Respecto a este hombre para la producción, Chul-Han (2014b) expresa que asistimos a una crisis de la libertad en tanto el hombre de hoy se encuentra inscrito en las dinámicas del neoliberalismo que le determinan y le van orientando la vida. Este autor introduce el concepto de sujeto proyecto, con el cual hace referencia a que el hombre, en un aparente uso de su libertad, elige esas formas de ser y estar en el mundo configurándose para sí mismo y para la sociedad en una especie de "proyecto" que lo define y alrededor del cual pone a girar toda su vida: Hoy creemos que no somos un sujeto sometido, sino un proyecto libre que constantemente se replantea y se reinventa. Este tránsito del sujeto al proyecto va acompañado de la sensación de 
libertad. [...]. El yo como proyecto cree haberse liberado de las coacciones externas y de las coerciones ajenas, se somete a coacciones internas y a coerciones propias en forma de una coacción al rendimiento y la optimización. (p. 12)

Este "proyecto" generalmente está asociado a la capacidad de cumplir metas, lo cual le permite tener una sensación de estar realizado y reforzar la creencia de ser libre. Así se convierte, ya no en esclavo de un tercero externo, sino de las propias ambiciones e ilusiones, las que han sido gestadas en su proyecto y que suelen tener un carácter de consumo. En este contexto, la posibilidad de elegir en libertad no existe. Como lo plantea Martínez (2008) citando a Heidegger en relación con la noción de finitud y límite, lo que ocurre en el marco del consumo y el sistema capitalista es que existen una serie de condicionamientos transmitidos a través de la práctica psicopolítica, entendida esta como una serie de mecanismos que permiten la intervención de la conducta sin que necesariamente medie la voluntad consciente del individuo.

Estos condicionamientos tienen que ver con lo que ha de ser la realización del sujeto, esto es, poder consumir ciertas cosas en particular, por ejemplo, ciertas marcas, poder tener cierto cuerpo y ser saludable de cierta manera, poder ser visto como un consumidor a la altura de lo que la sociedad valora como aceptado. Es de esta manera cómo se alcanzaría una realización sustentada en la experiencia de reconocimiento social que permite fortalecer la autoestima y la valía personal, pero que ya no necesariamente está orientada a alcanzar un nivel de autogobierno y gestión de sí que conduzcan a la autorrealización en el sentido del autoconocimiento y el desarrollo del propio potencial, como lo postula la psicología humanista existencial.

Es en este punto donde Cortina (2002) llama la atención sobre el hecho de que el problema del consumo no es el consumir como tal, sino "¿quién o quiénes están tomando las decisiones de consumo y quién o quiénes deberían tomarlas?" (p. 32). Esto quiere decir que, a la hora de decidir, tanto las marcas como el consumidor mismo han de tener una consciencia de ello pues tal asunto no podría estar en manos de uno solo de los actores del proceso, como pareciera suceder a través de las acciones psicopolíticas.

Retomamos la idea de sujeto proyecto en relación con el cuerpo y la salud para decir que el hombre contemporáneo tiene un marcado interés en ellos. Al parecer, debe prepararlos para que estén a tono como instrumentos para el cumplimiento de su proyecto. Para ello, tiene que estar permanentemente sometido a mantenerlos funcionales teniendo en cuenta que, a su vez, este hombre cuenta con el consumo, y la medicina dentro de él, para facilitárselo a través de unas prácticas de cuidado de sí que le propone. 
Tanto Chul-Han (2014b) como Lipovetsky (2016) se refieren a que, para el hombre de hoy, el cuerpo y la salud constituyen una especie de ideal a lograr a través de los cuales intenta alejarse de la realidad de la muerte, es decir, en términos de la psicología humanista existencial, trata de alejarse de la consciencia de finitud:

El trabajo y la mera vida están estrechamente relacionados. Son reacciones a la negatividad de la muerte. La defensa de la mera vida se agudiza hoy como agudización y fetichización de la salud. [...]. La salud es elevada a la condición de la 'gran diosa'. (Chul-Han, 2014b, p. 19)

En las sociedades hipermodernas, la salud acaba siendo una preocupación omnipresente, una obsesión, un tema presente a nivel cotidiano, tanto en las conversaciones como en los medios. [...]. Con vistas a cuidar su salud, los ciudadanos corrigen y reorientan su comportamiento cotidiano y su modo de vida. La medicina ya no se contenta con curar, hoy se dedica a prevenir enfermedades, a informar sobre los riesgos que corremos, a estimular las medidas de control y revisiones médicas. (Lipovetsky, 2016, p. 81)

Esta posición reafirma el lugar del cuerpo y la salud como categorías de consumo para el hombre de hoy y se conecta con los planteamientos de Estrada Mesa (2016) y Fajardo (2009) sobre el cuerpo y la salud atravesados por dinámicas de consumo. En este sentido, proponen verlos como una herramienta funcional sin la que el hombre al servicio de la producción no podría realizarse y sobre la cual puede, además, intervenir para alcanzar mayores eficiencias. Por ejemplo, por la vía de las tecnologías médicas, las rutinas de deporte y ejercicio, la alimentación, entre otras han terminado por convertirse en tendencias de comportamiento de consumo que permiten pensar que éste parece configurarse como un escenario para la "forja de sí".

Esta posibilidad de intervenir el cuerpo y la salud le crea al sujeto proyecto una sensación de poder prolongar la vida, de ajustarse a lo que el mercado le propone y, sobre todo, de no tener límites, con lo que se refuerza una vez más su sensación de libertad. A diferencia de los antiguos, hoy se cuidan el cuerpo y la salud más para disponerlos para el trabajo y la producción económica y menos para la "forja de sí".

Ahora bien, esta concepción de hombre eficiente y sus formas de ser y estar el mundo introduce una reflexión sobre el bienestar el cual se busca fundamentalmente a través del cuerpo y la salud, a la vez que se intentan eliminar las experiencias de angustia (Lipovetsky, 2016) y, por tanto, de límite. Esta concepción de bienestar así entendida se aleja de la propuesta de "buena vida" de Savater (2004), que incluye el límite como componente de la libertad. Sobre ella Papalini (2010) plantea una posición similar a la de Fajardo (2009) y que está en consonancia con Estrada Mesa (2016) y con Chul-Han (2014b) en 
la que se distingue el buen vivir del bienestar al referirlo a las dinámicas de competitividad y productividad propias del consumo:

El Buen Vivir se diferencia explícitamente de la concepción occidental de bienestar. Este último concepto, entendido como formas del "vivir mejor", trasunta la perspectiva del progreso y de la competencia. El vivir mejor [...] implica ganar más dinero, tener más poder, más fama [...] que el otro. El vivir mejor significa el progreso ilimitado, el consumo inconsciente; incita a la acumulación material e induce a la competencia. (Papalini, 2010, p. 52)

Estas posibilidades de transformar el cuerpo y la búsqueda de bienestar no solo tienen que ver con un cuerpo para la producción, sino que también tocan el cuerpo estético y el mundo psicológico (Lipovetsky, 2016), por lo que también se modifica para cumplir con unos ideales que redundarán en experiencias de incremento de autoestima por la vía de la aceptación social. Esta transformación del cuerpo hacia un ideal estético y psicológico se centra en una idea de cuerpo liviano (Lipovetsky, 2016) que elimine el riesgo de angustia y sufrimiento para crear, con ello, sensaciones de libertad y de dominio de sí. Desde esta óptica, el bienestar tiene que ver con un cuerpo que permite trabajar para poder producir y, a su vez, alcanzar un estado emocional que aleje todo malestar en ambas dimensiones. Así, no solo se consumen bienes en pro del cuidado del cuerpo y la salud, sino también servicios en pro del cuidado de la mente y del espíritu posibilitan el bienestar, tal como lo plantea Papalini (2010) y frente a lo cual Lipovetsky (2016) dice:

En lo últimos 20 años, las aspiraciones de las personas que frecuentan los gimnasios se han orientado más hacia la salud, el mantenimiento y la descomprensión que hacia la musculación. La idea de "forma" se identifica cada vez más con la armonía y el bienestar. (p. 84)

Ahora bien, para Lipovetsky (2016) esta búsqueda del bienestar y de la armonía, si bien están orientadas a la eficacia como se lee en Chul-Han (2014b), también conducen a un asunto relevante para el hombre del hipermodernismo': el hedonismo. Este se refiere a que el hombre de hoy está más pendiente de sí mismo y de sus gratificaciones físicas y psicológicas, lo cual puede verse como un rostro del "cuidado de sí" y ofrece un marco de resignificación de la vida que toma forma concreta en el cuerpo y la salud a través de actos de consumo.

Todas estas prácticas se buscan como fuente de mayor bienestar y no únicamente como antidepresivos para "levantar la moral". La consagración del mayor bienestar obedece a una amplitud del sobreesfuerzo como a la nueva legitimidad de la que gozan la atención a uno mismo, los placeres sensitivos, "el deseo de sentirse bien en el propio cuerpo y en la propia cabeza" (Lipovetsky, 2016, p. 85).

\footnotetext{
Con este término Lipovetsky nombra la era de la ruptura de las mega estructuras de la modernidad.
} 
Tal resignificación de la vida hacia el hedonismo se da en el marco del capitalismo de consumo o capitalismo de "seducción" (Lipovetsky, 2016) con su característica de ligereza como tendencia a preferir lo liviano y lo ágil que le ha permitido al hombre de hoy liberarse de las pesadas estructuras de la modernidad para dar paso a una mayor individualización que le permite, no solamente elegir y decidir con mayor libertad, sino también configurarse a sí mismo desde esta para, así, darle un mayor lugar a asuntos como el goce de la vida y acceder a lo bello y sensible como condición humana y natural. De ahí se infiere que el cuerpo y la salud toman para este hombre un nuevo lugar, se vuelven centrales como vías para lograr lo deseado gracias a la sensación y la percepción.

La importancia de esta revolución es considerable, en la medida en que abre horizontes casi ilimitados en los dominios del entorno material y natural, de la salud, de la vida misma. Lo ligero, que era la más insignificante y fútil, es hoy la mayor fuerza de transformación del mundo. En la era de la hipermodernidad no es el poder sobre lo pesado lo que cambia la faz del mundo, sino el poder sobre lo ultraligero. (Lipovetsky, 2016, p. 13)

En esta línea de ideas, para el hombre hipermoderno consumir aparece como una vía para dar lugar al individualismo hedonista, pues le permite concretar en tal práctica muchos de sus deseos y aspiraciones para sentirse quien quiere ser, realizado y que también hace sus elecciones en torno a la "forja de sí". En esta medida se puede pensar el consumo como un escenario para la proyección de la identidad que, sin duda, influye de manera significativa en la configuración de esta. Es así como los diferentes actores de este fenómeno, el consumidor y las marcas comerciales, tienen allí una gran responsabilidad, más aún cuando tal proyección (Chul-Han, 2014a) se está dando a través del cuerpo y la salud como instrumentos para ello.

Claramente el cuerpo y la salud aparecen, entonces, como experiencia de hedonismo y una de las manifestaciones más representativas de ello es el cuerpo delgado como uno de los intereses marcados en relación con estas categorías, pues "con esta intensificación del ideal de delgadez se pone en marcha una de las figuras ejemplares de la civilización de lo ligero" (Lipovetsky, 2016, p. 94). Este ideal de delgadez, reforzado por las marcas comerciales en sus productos y mensajes publicitarios, ha ido penetrando la psicología de los individuos hasta convertirse en pauta central de las decisiones frente a cómo vivir y, por ende, frente a la "forja de sí". Este ideal reporta en cierta medida sensaciones de libertad asociadas a la facilidad de movimiento, a fluir, a la eliminación de las cargas y de las angustias de la vida, pero, sobre todo, a la aceptación social, con lo que parece conducir más rápidamente a la realización, entendida esta como el cumplimiento de metas. 
Sin embargo, tal como lo plantea Lipovetsky (2016), este ideal conlleva la obligación de ser alcanzado. En este sentido, se convierte en carga para sí mismo, pues le exige al individuo una serie de requisitos que, a la larga, terminan esclavizándolo a sus propias ambiciones, alejándolo de toda posibilidad de libertad, tal como lo enuncia también Chul-Han (2014b) en relación al sujeto proyecto. Sobre este ideal de delgadez como ausencia de libertad, Lipovetsky (2016) dice:

La revolución de lo ligero es inseparable de la cultura del individuo pragmático, responsable confeso de su cuerpo y al mismo tiempo cada vez más situado bajo el dominio de la norma estandarizada de la belleza y la juventud. En nuestra época es patente el 'diseño' hiperindividualista del cuerpo y al mismo tiempo la mayor influencia social que ejerce el modelo uniforme e implacable de la estética de la delgadez. Hay menos culpa moral, pero más ansiedad narcisista, más voluntad autoconstructora, pero también más consumismo desenfrenado para conseguir o conservar la 'línea'. (p. 100)

Así, este ideal de delgadez como concreción de las experiencias de cuerpo y salud conlleva una angustia asociada al no poder lograrlo, de lo cual se desprenden una serie de asuntos que trastocan la estabilidad psicológica del individuo, principalmente la autoestima y la valía de sí las cuales se deterioran cada vez que un individuo, en la búsqueda por autopercibirse según el cuerpo deseado y exigido por los patrones de salud, ratifica que su esfuerzo para alcanzar lo propuesto se ha perdido, "como la recuperación del peso se vive como falta de voluntad, las esperanzas se transforman en sentimiento de fracaso, culpabilidad, pérdida de autoestima" (Lipovestky, 2016, p. 113).

Es así como Chul-Han (2014b) y Lipovetsky (2016) coinciden en que el hombre está siendo cada vez más esclavo de una dinámica de consumo que le propone unos ideales de eficacia y belleza como modos de vida y unos referentes de cuerpo y salud que parecen alcanzables porque se muestran a través de una aparente promesa de libertad en un escenario como el del consumo. En éste él cree poder elegir porque se le ofrecen opciones diversas en las manera, pero en el que el fin sigue siendo el mismo objetivo: cumplir un ideal que se convierte en su propio verdugo y lo aleja de la experiencia de elegir y decidir en libertad, como lo aspiraran los postulados de la psicología humanista existencial. Esto quiere decir que los límites aquí no los define la condición existencial como tal, sino que los define el consumo y las marcas dentro de éste.

Con esto es evidente el riesgo de que en las experiencias de ligereza, lo frívolo, lo que aleja la profundidad de la vida, sea lo que se imponga y los individuos y las sociedades incapaces, conscientemente o no, de establecer límites, caigan en estados de desesperación extrema que conlleven a un deterioro del cuerpo y la salud marcados por la dependencia o por una cierta sensación de "no poder lograrlo", lo cual podría coartar la libertad de elección y decisión. 
Frente a este riesgo de la dependencia y el consecuente efecto en la libertad, Lipovetsky (2016), nombra la necesidad de regulación estableciendo unos niveles de ligereza, detallando, de manera similar a como lo hace Cortina (2002), en la responsabilidad que llevará al establecimiento de la mesura en las decisiones:

El peligro no es la ligereza frívola sino su hipertrofia, cuando invade la vida y asfixia las demás dimensiones esenciales: la reflexión, la creación, la responsabilidad ética o política. La ligereza frívola no es dramática por sí misma, pero llega a serlo cuando se impone como estilo de vida dominante hasta el punto de aniquilar lo que enriquece la vida humana. ¿Qué es más aburrido que la sola frivolidad? Al mismo tiempo, la vida sin ligereza superficial es triste y agobiante. Lo que hay que denunciar es la ligereza fútil que se propone como ideal supremo de la vida. (Lipovetsky, 2016, p. 335)

En esta medida, Lipovetsky (2016) y Chul-Han (2014b) le dan un lugar relevante al cuerpo y a la salud. Mientras desde Chul-Han puede decirse que cuerpo y salud están al servicio del hombre productivo/eficiente, para Lipovetsky éstos sirven como vía para la experiencia del goce hedónico.

Así, el hombre de hoy cuida de sí a través de prácticas sobre su cuerpo y su salud para permanecer funcional y producir, así como para garantizarse un goce de la vida. El consumo no solo plantea los ideales de ser, sino que ofrece las formas para llegar a ser, con lo que se coartan sus posibilidades de libertad que lo esclavizan a dichos ideales. En este sentido, se destaca que el consumo no solamente tiene el poder para proponer ideales, sino que también tiene la capacidad de movilizar la conducta social hacia su búsqueda, moldeándola y llevando a los individuos a una resignificación del cuerpo y la salud en un sentido idealizado, medicalizado y funcional para el trabajo y la productividad. Este el contexto que se constituye como escenario para la "forja de sí". Para efectos de sintetizar la propuesta reflexiva de este artículo, se presenta en el mapa conceptual de la página siguiente.

\section{Conclusiones}

Entender el fenómeno de consumo desde miradas que se asemejan a las figuras del "gran hermano" y del panóptico de Foucault que hoy han llegado también al mundo de la digitalización (Chul-Han, 2014b) a través de los dispositivos tecnológicos de la comunicación y la vida en redes sociales, permite afirmar que, en efecto, a través de las estrategias de mercadeo y publicidad, se logra una modificación de conducta al servicio de la mera generación de riqueza para las marcas y otros actores del consumo interesados en ello. Así, el poder de las marcas para "manipular al consumidor" es claramente posible.

La psicología humanista existencial, tal como lo plantean Ortiz-Pabón y Sanabria-Correa (2015), permite pensar un hombre activo que tiene una 


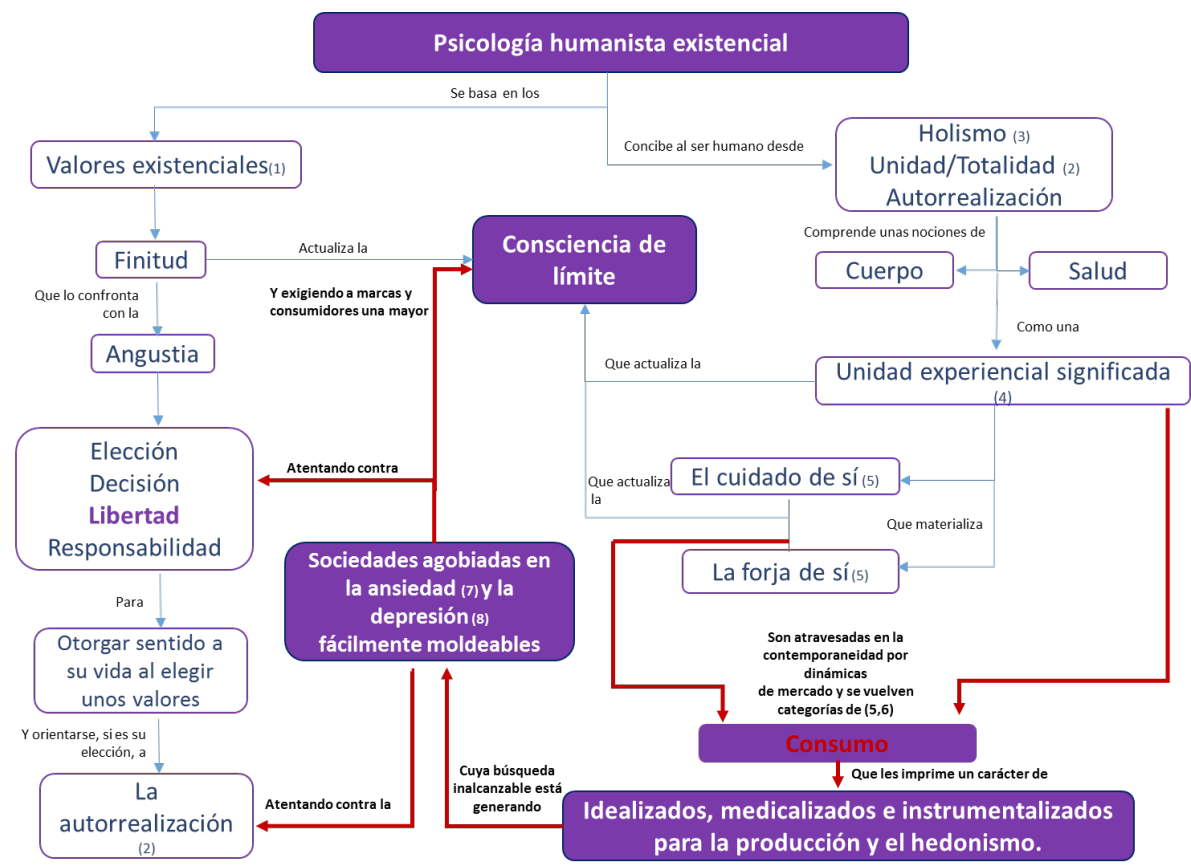

(1) Martínez, Y.A. 2009. (2) Villegas, B. 1986. (3) Latner, 1994; (4) Ortiz-Pabón y Sanabria-Castro, 2015. (5) Estrada, D.A., 2016. (6) Fajardo, J.A. 2009. (7) Lipovetesky, G. 2016. (8). Chul Han, B. 2014b.

Figura 1. Relación temática gráfica del artículo Fuente: elaboración propia.

capacidad de intervenir sobre sí mismo y sobre el medio, con posibilidad de libertad y responsabilidad. Así, apunta, si es su elección, a forjarse una buena vida con miras a su autorrealización y a la de la sociedad que lo ha acogido. Y define como su objeto de estudio un hombre que, entre otras características, tiene unas capacidades de consciencia y simbolización para representarse el mundo, una posibilidad para establecer relaciones profundas, un potencial creativo y que se enmarca dentro de un sistema de valores para orientar su vida (Villegas, 1986). Esta es una mirada que permite introducir otros puntos de vista para el análisis del poder de las marcas sobre las elecciones de sus consumidores y sobre el consumo como fenómeno social en el marco de las categorías "cuerpo" y "salud" que llama a una postura de mayor exigencia para el consumidor y también para las marcas, pues si bien no se es totalmente libre, sí existe, al menos desde esta postura teórica, una posibilidad para ello.

Cuando está en riesgo la capacidad humana de darse cuenta y hacer consciencia, el individuo termina dejando de ser sí mismo, desconoce al otro y a lo otro. Tal vez es por ello que vemos hoy sociedades inmersas en unas formas de vida determinadas por la ligereza frívola, en términos de Lipovetsky, para 
quienes la experiencia de cuerpo y salud termina siendo resignificación de la vida desde el agotamiento, la desesperación interior, la depresión y un cierto desasosiego que, a su vez, las expone más y las hace más vulnerables al sin sentido, a una ausencia de experiencias de libertad que paradójicamente convive con la "creencia" de ser libre.

Aquí está el dilema existencial del consumo: el hombre vive para el afuera según los mandatos ideales del consumo de seducción que se materializan en la experiencia de cuerpo y salud, mientras que se va destrozando por dentro. Quizá esto deba a que no se hace cargo de "hacerse a sí mismo", de quién es y quién quiere ser, tal vez porque debería seguir la guía del "autogobierno" para tomar lugar en la economía de mercado desde ahí, una circunstancia social que no se puede evitar pero dentro de la cual sí podría elegir cómo vivir. Aquí estaría la libertad. Lo que intensifica el dilema es que está en juego un asunto psicológico de gran relevancia, esto es, la falta de estima, de valía personal, el desconocimiento del propio potencial, la dificultad para establecer límites y la necesidad de compensación. Para dar respuesta a esta condición de ansiedad el hombre de hoy sigue las propuestas de "cuidado de sí" que le vienen desde las marcas, que se concretan en prácticas sobre el cuerpo y la salud, pero que no están orientadas a una "forja de sí", entendida esta como preparación para asumir la vida y su complejidad, sino más bien a un moldeamiento de la conducta que casi siempre lo somete al rendimiento en un aparato productivo en el marco de un sistema capitalista de mercado que lo convoca al goce hedónico y lo esclaviza a los ideales de vida que le propone, debilitándolo más que fortaleciéndolo para afrontar la experiencia de la vida.

Tales prácticas de "cuidado de sí" no parecen estar mediadas por unos procesos de consciencia que le permitan dar cuenta al individuo de las intenciones de las mismas, como tampoco prever la posibilidad de daño que puedan implicar, en particular en términos del sentido idealizado, medicalizado e instrumental que se le otorga al cuerpo y a la salud que no parecen estar orientadas a una autorrealización en la intención de desarrollo y trascendencia que propone la psicología humanista existencial, sino más bien a una realización en el sentido material.

La educación de los individuos para una "forja de sí" no parece ser de interés en las lógicas del consumo y el hombre de hoy lo ha aceptado así. Quizá esto se debe al hecho de que buscarla exige un esfuerzo de consciencia y una dedicación no solo en términos físicos y de tiempo, sino también en términos cognitivos, morales y espirituales, y, por otro lado, porque los resultados de ello pueden tener un costo social que redunda en unas implicaciones sobre la autoestima y la aceptación, condiciones importantes para el mantenimiento del equilibrio psíquico y la adaptación social. 
En esta realidad en la que, para el hombre de hoy, el consumo se configura como escenario para la "forja de sí", este artículo propone, a partir de los postulados de la psicología humanista existencial, un llamado a que los individuos potencien su capacidad de autogestión por la vía del hacer consciencia de sí, del otro y de lo otro. Para ello se sugiere una posibilidad de consciencia de límite que permita la autorregulación y "forja de sí" para lanzarse a la autorrealización y evitar o minimizar la posibilidad de daño, teniendo en cuenta que para esta postura psicológica las experiencias de ansiedad y angustia (De Castro y García, 2011), son en sí mismas experiencias del límite (Ortiz-Pabón y Sanabria-Correa, 2015) que se viven en el cuerpo y atraviesan la salud. Además, como lo plantea Chul-Han (2014b), al hablar de la depresión y Lipovetsky (2016), al hablar de ansiedad, estas son consecuencias que devienen de las formas de vida que el capitalismo de consumo le propone al hombre de hoy. Este elemento refuerza aún más la posibilidad de que esta perspectiva psicológica se extienda al análisis del consumo y de las relaciones entre marcas y consumidores, pues justo lo que esta busca es que el individuo se conozca y se autorregule en su experiencia cotidiana de la vida, en la cual hoy están el consumo y su interés por un cuerpo y una salud idealizados, medicalizados e instrumentalizados.

\section{Agradecimientos}

Este artículo hizo parte del trabajo de grado de la autora para optar por el título de magíster en Comportamiento del Consumidor de la Universidad Pontificia Bolivariana, Escuela de Ciencias Sociales, Facultades de Publicidad y Psicología, Medellín.

\section{Referencias}

Canga Sosa, M. (2017). Algunos interrogantes sobre la relación entre publicidad, consumo y Buen Vivir. Chasqui. Revista Latinoamericana de Comunicación, (134), 221-236.

Chul-Han, B. (2014a). El enjambre. Barcelona, España: Herder.

Chul-Han, B. (2014b). Psicopolítica. Barcelona, España: Herder.

Congreso de la República de Colombia (2011). Estatuto del consumidor. Ley 1480 de 2011. Bogotá: Congreso de la República de Colombia.

Cortina, A. (2002). Por una ética del consumo. Madrid: Tauros.

De Castro, A. M. y García M. (2011). Psicología clínica. Fundamentos existenciales. Barranquilla, Colombia: Universidad del Norte.

Estrada-Mesa, D. A. (2015). La medicina antigua: Una ética existencial en Michel Foucault. Praxis Filosófica, (42), 134-156.

Fajardo, J. A. (2009). Yoga, cuerpo e imagen: espiritualidad y bienestar, de la terapia a la publicidad. Universitas Humanísitca, (68), 11-47. 
Franca-Tarragó, O. (2008). Ética para psicólogos: introducción a la psicoética. Bilbao: Desclée de Brouwer. Latner, J. (1994). Fundamentos de la Gestalt. Santiago de Chile, Chile: Cuatro Vientos.

Lipovetsky, G. (2016). De la ligereza. Barcelona, España: Anagrama.

López, H. J. (2001). Investigación Cualitativa y participativa: Un enfoque hermenéutico y Critico Social en Psicología y Educación Ambiental. Medellín, Colombia: Universidad Pontificia Bolivariana.

Martínez M. M. (1982). La psicología humanista: fundamentación epistemológica, estructura y método. México: Trillas.

Martínez, Y. A. (2009). Filosofía existencial para terapeutas y uno que otro curioso. México: LAG Ediciones.

Molina, J. y Morán A. (2008). Que viva la publicidad viva. Bogotá, Colombia: Lemoine Editores.

Ortiz-Pabón, N. y Sanabria-Correa, L. F. (2015). La relación entre cuerpo y salud como forma de ser-enel-mundo: una mirada desde la psicología humanista existencial (tesis de pregrado) Universidad Pontificia Bolivariana, Medellín, Colombia.

Papalini, V. (2017). El buen vivir, entre las tácticas del consumo y las cosmogonías ancestrales. Chasqui. Revista Latinoamericana de Comunicación, (134), 43-59.

Quitmann, H. (2006). Psicología humanística. Bogotá, Colombia: Herder.

Savater, F. (2004). Ética para Amador. Barcelona, España: Ariel.

Schiffman, G. y Kanuk, L. (2010). Comportamiento del consumidor. México: Pearson.

Solomon, M. R. (2013). Comportamiento del consumidor. México: Pearson.

Universidad Pontificia Bolivariana (2017). El nuevo mundo del lujo. Conferencia dictada en el marco de la estrategia "En Contexto". Escuela de Verano UPB. Medellín, 15 de agosto.

Vargas, N. (2014). Zygmunt Bauman: La modernidad líquida como una crítica a la sociedad. Medellín, Colombia: Universidad Pontificia Bolivariana.

Villegas, B. (1986). La psicología humanista: historia, concepto y método. Barcelona, España: Facultad de Psicología Universidad de Barcelona. 